\title{
Anti-allergic effect of the naturally-occurring conjugated linolenic acid isomer, jacaric acid, on the activated human mast cell line-1
}

\author{
WAI NAM LIU and KWOK NAM LEUNG \\ Biochemistry Programme, School of Life Sciences, The Chinese University \\ of Hong Kong, Shatin, Hong Kong, SAR, P.R. China
}

Received June 24, 2015; Accepted September 9, 2015

DOI: $10.3892 /$ br.2015.517

\begin{abstract}
The present study aimed to investigate the immunomodulatory effect of jacaric acid, a naturally-occurring conjugated linolenic acid isomer that can be found in jacaranda seed oil, on the activated human mast cell line-1 (HMC-1). Our previous studies have demonstrated that jacaric acid only exerted minimal, if any, cytotoxicity on normal murine cells. In the present study, jacaric acid at concentrations $\leq 100 \mu \mathrm{M}$ did not exhibit direct cytotoxicity on human peripheral blood mononuclear cells after $72 \mathrm{~h}$ of incubation, as determined by the MTT reduction assay. By contrast, jacaric acid could alleviate the calcium ionophore A23187 and phorbol 12-myristate 13-acetate-triggered allergic response in the HMC-1 cells at concentrations that were non-cytotoxic to the HMC-1 cells. Following pre-treatment with jacaric acid, the secretion of two inflammatory mediators, $\beta-N$-acetylglucosaminidase and tryptase, as well as the Thelper 2 cytokines [interleukin(IL)-4 and IL-13] was significantly reduced in HMC-1 cells. The alleviation of allergic response was accompanied by downregulation of the matrix metalloproteinase- 2 and -9 proteins and upregulation of the tissue inhibitor of metalloproteinase-1 protein. Collectively, the results indicated that the naturally-occurring jacaric acid exhibits a suppressive effect on the allergic response in activated human mast cells in vitro, and this could not be attributed to the direct cytotoxicity of jacaric acid on the treated cells.
\end{abstract}

\section{Introduction}

Conjugated fatty acids (CFAs) refer to the positional and geometric isomers of polyunsaturated FAs with conjugated

Correspondence to: Professor Kwok Nam Leung, Biochemistry Programme, School of Life Sciences, The Chinese University of Hong Kong, 12 Chak Cheung Street, Shatin, Hong Kong, SAR, P.R. China

E-mail:knleung@cuhk.edu.hk

Key words: anti-allergic effect, $\beta-N$-acetylglucosaminidase, conjugated linolenic acids, interleukins, jacaric acid, mast cells, matrix metalloproteinases, tryptases double bonds, in which 2 carbon-carbon double bonds are separated solely by one carbon-carbon single bond (1). Common CFA isomers, such as conjugated linoleic acids (CLAs) and conjugated linolenic acids (CLNAs), can be found naturally in meat or dairy products of ruminant animals (2) and different plant seed oils (3), respectively. CLAs have been studied most extensively due to their diverse metabolic and physiological effects $(4,5)$. In recent years, CLNAs have received increasing attention as their relative abundance in certain plant seed oils (30-70\% of total lipids) was much higher compared to that of CLAs $(<1 \%$ of total lipids) $(3,6)$. Previous in vitro and in vivo studies have demonstrated that CLNAs exhibit pleiotropic physiological and pharmacological activities, including anti-carcinogenic, anti-inflammatory, anti-obese, antioxidative and immunomodulatory properties $(7,8)$. An earlier study by Ike et al (9) showed that $\alpha$-eleostearic acid (9Z, 11E, 13E-CLNA isomer) isolated from bitter gourd could induce interferon- $\gamma$ production in mice treated with heat-inactivated Propionibacterium acnes, suggesting that T helper 1 (Th1) cellular immunity can be activated by $\alpha$-eleostearic acid, which is responsible for the defense against intracellular parasitic infection. By contrast, Yamasaki et al (10) reported that consumption of pomegranate seed oil that is rich in punicic acid (9Z, 11E, 13Z-CLNA isomer) could ameliorate the function of B cells, which have a key role in the humoral immune response. These studies started to explain the immunostimulatory activities of CLNAs, however, the anti-allergic activity of CLNAs and their modulatory effects on mast cells have not yet been investigated. In the present study, jacaric acid (8Z, 10E, 12Z-CLNA isomer; Fig. 1) alleviated the allergic response in calcium ionophore A23187 (Iono) and phorbol 12-myristate 13-acetate (PMA)-activated human mast cells by reducing the release of inflammatory mediators and Th2 cytokines, and by modulating the protein expression levels of matrix metalloproteinases (MMPs).

\section{Materials and methods}

Chemicals and reagents. Jacaric acid (8Z, 10E, 12Z-CLNA isomer) used in the study, with an estimated purity $>97 \%$, was purchased from Larodan Fine Chemicals AB (Limhamn, Sweden). The stock solution $(0.2 \mathrm{M})$ was prepared by dissolving the powder in sterile, cell culture-tested ethanol 
(Sigma-Aldrich, St. Louis, MO, USA). All other chemicals, unless otherwise stated, were purchased from Sigma-Aldrich.

Culture of cell line. Human mast cell line-1 (HMC-1) was a generous gift from Professor C.K. Wong of the Department of Chemical Pathology, The Chinese University of Hong Kong (Shatin, Hong Kong, SAR, China) (11). The cells were maintained in RPMI-1640 medium (Gibco, Thermo Fisher Scientific, Grand Island, NY, USA) supplemented with $10 \%$ fetal bovine serum (Gibco, Thermo Fisher Scientific) and 1\% antibiotics $(100 \mathrm{U} / \mathrm{ml}$ penicillin $\mathrm{G}, 100 \mu \mathrm{g} / \mathrm{ml}$ streptomycin sulfate and $0.25 \mu \mathrm{g} / \mathrm{ml}$ amphotericin B in $0.85 \%$ saline from Gibco, Thermo Fisher Scientific) in a humidified incubator containing $5 \% \mathrm{CO}_{2}$ in air at $37^{\circ} \mathrm{C}$.

The procedures for the stimulation of HMC-1 cells were modified from a previously described method (12). In brief, HMC-1 cells $\left(3 \times 10^{5}\right.$ cells $\left./ \mathrm{ml}\right)$ were pre-treated with different concentrations of jacaric acid at $37^{\circ} \mathrm{C}$ for $72 \mathrm{~h}$ in $175-\mathrm{cm}^{2}$ tissue culture flasks. Following incubation, cells were centrifuged at $400 \mathrm{x} \mathrm{g}$ for $5 \mathrm{~min}$, washed with phosphate-buffered saline three times and $3 \times 10^{6}$ cells were transferred to a flat-bottomed 6-well microtiter plate in $1 \mathrm{ml}$ complete RPMI medium, and were activated with $2 \mu \mathrm{M}$ Iono and $40 \mathrm{nM}$ PMA at $37^{\circ} \mathrm{C}$ for $6 \mathrm{~h}$ for the further assays.

Cytotoxicity assay. Human peripheral blood mononuclear cells (PBMCs) were prepared from the fresh human buffy coats supplied by the Hong Kong Red Cross Blood Transfusion Service (Kowloon, Hong Kong, SAR, China). The PBMCs used were a generous gift from Professor C.K. Wong of the Department of Chemical Pathology, The Chinese University of Hong Kong (13). Briefly, the viability of jacaric acid-treated HMC-1 cells and PBMCs was measured by the colorimetric MTT reduction assay, as described previously (14). Briefly, HMC- 1 cells $\left(3 \times 10^{5} / \mathrm{ml}\right)$ and PBMCs $\left(3 \times 10^{6} / \mathrm{ml}\right)$ seeded in a flat-bottomed 96 -well microtiter plate were incubated at $37^{\circ} \mathrm{C}$ with different concentrations of jacaric acid for various periods of time, and the cell viability was recorded by a Benchmark microplate reader (Bio-Rad Laboratories, Inc., Hercules, CA, USA). To further confirm the viability of jacaric acid-treated HMC-1 cells followed by Iono- and PMA-activation, the cells were counted by the trypan blue exclusion assay and the percentages of necrotic cells in the samples were also determined by the annexin V-green fluorescent protein (GFP)/propidium iodide (PI) dual staining assay using the FACSCanto $^{\mathrm{TM}}$ flow cytometer (BD Biosciences, Franklin Lakes, NJ, USA) as described previously (14).

Determination of $\beta$ - $N$-acetylglucosaminidase (NAG) release in $H M C-1$ cells. The measurement was performed according to the manufacturer's instructions in the NAG assay kit (Sigma-Aldrich) with slight modifications. Briefly, HMC-1 cells $\left(3 \times 10^{5}\right.$ cells $\left./ \mathrm{ml}\right)$ were incubated with different concentrations of jacaric acid at $37^{\circ} \mathrm{C}$ for $72 \mathrm{~h}$ in $175-\mathrm{cm}^{2}$ tissue culture flasks and the treated cells $\left(3 \times 10^{6}\right)$ were further stimulated by $2 \mu \mathrm{M}$ Iono and $40 \mathrm{nM}$ PMA at $37^{\circ} \mathrm{C}$ for $6 \mathrm{~h}$ in a 6 -well plate. Following incubation, the stimulated cells were centrifuged at $400 \mathrm{x}$ g for $5 \mathrm{~min}$, and $50 \mu \mathrm{l}$ cell-free supernatant or cell lysate was transferred to the well of a flat-bottomed 96-well plate. A total of $50 \mu \mathrm{l}$ of $0.09 \mathrm{M}$ sodium citrate solution ( $\mathrm{pH} 4.7$ )

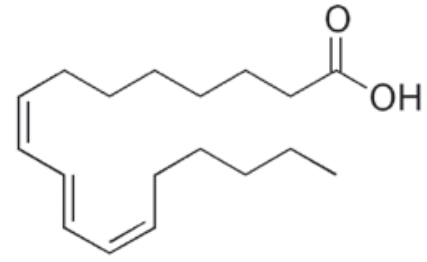

Figure 1. Chemical structure of jacaric acid (8Z, 10E, 12Z-conjugated linolenic acid isomer).

containing $1 \mathrm{mg} / \mathrm{ml}$ 4-nitrophenyl- $N$-acetyl- $\beta$-D-glucosami nide was added to the wells and incubated at $37^{\circ} \mathrm{C}$ for $30 \mathrm{~min}$ for color development. The enzymatic reaction was terminated by adding $200 \mu \mathrm{l}$ of sodium carbonate solution [0.4 M (pH 11.6)] and the absorbance at $405 \mathrm{~nm}$ was measured by the Benchmark microplate reader. The concentrations of NAG in the samples were expressed in $\mathrm{U} / \mathrm{ml}$, in which 1 unit of NAG will hydrolyze 1 nanomole of 4-nitrophenyl- $N$-acetyl- $\beta$-D-glucosaminide to $p$-nitrophenol and $N$-acetyl- $\beta$-D-glucosaminide per min at $\mathrm{pH} 4.7$ and $37^{\circ} \mathrm{C}$. The percentage of NAG release was calculated as follows: \% NAG release $=($ concentration of NAG in supernatant)/(concentration of NAG in supernatant and whole cell lysate) x100.

Measurement of tryptase release in HMC-1 cells. The assessment was performed according to the manufacturer's instructions in the Mast Cell Degranulation Assay kit (Millipore Corp., Billerica, MA, USA). HMC-1 cells $\left(3 \times 10^{5}\right.$ cells $\left./ \mathrm{ml}\right)$ were incubated with different concentrations of jacaric acid at $37^{\circ} \mathrm{C}$ for $72 \mathrm{~h}$ in $175-\mathrm{cm}^{2}$ tissue culture flasks and the treated cells $\left(3 \times 10^{6}\right)$ were further stimulated by Iono and PMA at $37^{\circ} \mathrm{C}$ for $6 \mathrm{~h}$ in a 6 -well plate. Following incubation, the stimulated cells were centrifuged at $400 \mathrm{x} \mathrm{g}$ for $5 \mathrm{~min}$, and $180 \mu \mathrm{l}$ cell-free supernatant was transferred to the well of a flat-bottomed 96-well plate. A total of $20 \mu 1$ of tryptase substrate was added to each well and the samples were incubated at $37^{\circ} \mathrm{C}$ for $2 \mathrm{~h}$. The absorbance at $405 \mathrm{~nm}$ was measured by the Benchmark microplate reader and the concentrations of tryptase in the samples were quantified with reference to a series of tryptase positive control solutions with concentrations ranging from 0 to $10,000 \mathrm{ng} / \mathrm{ml}$.

Assessment of cytokine secretion by ELISA. To determine the secretion of interleukin (IL)-4 and IL-13, the corresponding ELISA kit was used (ExCell Biology, Inc., Shanghai, China). Briefly, HMC-1 cells $\left(3 \times 10^{5}\right.$ cells $\left./ \mathrm{ml}\right)$ were incubated with different concentrations of jacaric acid at $37^{\circ} \mathrm{C}$ for $72 \mathrm{~h}$ in $175-\mathrm{cm}^{2}$ tissue culture flasks and the treated cells $\left(3 \times 10^{6}\right)$ were further stimulated by $2 \mu \mathrm{M}$ Iono and $40 \mathrm{nM}$ PMA at $37^{\circ} \mathrm{C}$ for $6 \mathrm{~h}$ in a 6 -well plate. The cell-free supernatant was transferred to another 96-well plate provided in the ELISA kit. Subsequently, the absorbance at $405 \mathrm{~nm}$ was measured by the Benchmark microplate reader.

Western blotting. Protein expression levels were determined by the western blotting technique with the aid of a panel of specific antibodies. HMC- 1 cells $\left(3 \times 10^{5}\right.$ cells $\left./ \mathrm{ml}\right)$ were incubated with different concentrations of jacaric acid at $37^{\circ} \mathrm{C}$ for $72 \mathrm{~h}$ in $175-\mathrm{cm}^{2}$ tissue culture flasks and the treated HMC-1 cells were 
transferred to a 6-well plate and sensitized in the presence of $2 \mu \mathrm{M}$ Iono and $40 \mathrm{nM}$ PMA at $37^{\circ} \mathrm{C}$ for $6 \mathrm{~h}$. After incubation, the cell pellet was collected and total protein was extracted by the cell lysis buffer. Protein concentration was measured by the Bradford reagent and the protein sample was resolved on $12 \%$ polyacrylamide gels and transferred to polyvinylidene defluoride membranes. The membrane was first incubated with the following primary antibodies: Rabbit anti-MMP-2 (CST-4022S), anti-MMP-9 (CST-3852S), anti-tissue inhibitor of metalloproteinase-1 (TIMP-1) (CST-8946S) (Cell Signaling Technology, Inc., Danvers, MA, USA) and mouse anti- $\beta$-actin antibody (SC-A5316) (Santa Cruz Biotechnology, Inc., Dallas, TX, USA), followed by incubation with mouse IgG horseradish peroxidase-conjugated secondary antibody (GE-NA931) or rabbit $\mathrm{IgG}$ horseradish peroxidase-conjugated secondary antibody (GE-NA934) (GE Healthcare, Buckinghamshire, UK and finally developed with the enhanced chemiluminescence reagent (Santa Cruz Biotechnology, Inc.).

Statistical analysis. Each experiment was repeated at least three times and only the results of the most representative experiments are shown. The data are expressed as the arithmetic mean \pm standard error. One-way analysis of variance was used for statistical analysis, and $\mathrm{P}<0.05$ was considered to indicate a statistically significant difference.

\section{Results}

Jacaric acid exhibits no direct cytotoxicity on HMC-1 cells and PBMCs. To investigate whether jacaric acid was cytotoxic to the HMC-1 cells or PBMCs, the colorimetric MTT reduction assay was employed. Fig. 2A shows that jacaric acid at concentrations $\leq 8 \mu \mathrm{M}$ exhibited no significant cytotoxicity to the HMC- 1 cells ( $>90 \%$ cell viability) after $72 \mathrm{~h}$ of incubation when compared with the solvent control. Additionally, the viability of jacaric acid-treated HMC-1 cells following Iono- and PMA-activation was examined by the trypan blue exclusion assay and by the annexin V-GFP/PI dual staining assay. As shown in Fig. 2B and C, the cell viability of HMC-1 cells and the percentage of the necrotic cells respectively did not differ significantly between the jacaric acid-treated group and the solvent-treated control. Notably, the viability of the PBMCs remained $>90 \%$ when the cells were incubated with $\leq 100 \mu \mathrm{M}$ jacaric acid for 6, 24, 48 and $72 \mathrm{~h}$ (Fig. 3), suggesting that jacaric acid was neither cytotoxic to the HMC-1 cells, nor to the PBMCs under the prescribed experimental conditions.

Jacaric acid suppresses the release of NAG and tryptase from HMC-1 cells. Mast cells have a well-known central role in allergic response by releasing pharmacologically active inflammatory mediators, which cause the symptoms of allergic inflammatory reaction (15). Common inflammatory mediators, including NAG and tryptase, are potent markers of allergic disease (16). In the present study, the release of NAG and tryptase in HMC-1 cells was increased by 2-fold upon activation with Iono and PMA (data not shown), suggesting that the combined use of Iono and PMA can elicit an allergic response. To investigate whether jacaric acid can exhibit an anti-allergic response, jacaric acid-treated HMC-1 cells were stimulated by $2 \mu \mathrm{M}$ Iono and $40 \mathrm{nM}$ PMA, and the release
Table I. Jacaric acid suppresses $\beta$ - $N$-acetylglucosaminidase and tryptase release in $\mathrm{HMC}-1$ cells.

\begin{tabular}{lccc}
\hline \multirow{2}{*}{$\begin{array}{l}\text { Release of } \\
\text { inflammatory } \\
\text { mediator }\end{array}$} & \multicolumn{3}{c}{ Concentration of jacaric acid, $\mu \mathrm{M}$} \\
\cline { 2 - 4 } & 0 & 2 & 4 \\
\hline NAG, $\%$ & $31.80 \pm 3.82$ & $25.85 \pm 2.02$ & $16.32 \pm 1.02^{\mathrm{a}}$ \\
Tryptase, $\mathrm{U} / \mathrm{ml}$ & $503.93 \pm 25.73$ & $496.38 \pm 26.46$ & $408.85 \pm 20.38^{\mathrm{a}}$ \\
\hline
\end{tabular}

Percentage of $\beta$ - $N$-acetylglucosaminidase (NAG) release was calculated as follows: \% NAG release $=($ concentration of NAG in supernatant)/(concentration of NAG in supernatant and whole cell lysate) $x 100$. ${ }^{\mathrm{P}}<0.001$. HMC-1, human mast cell line- 1 .

A

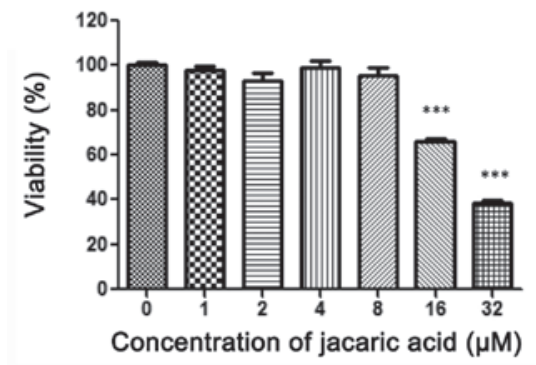

B

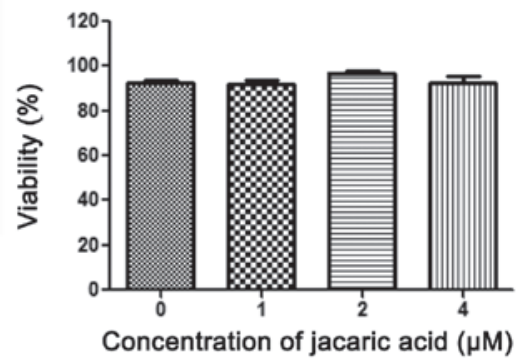

C

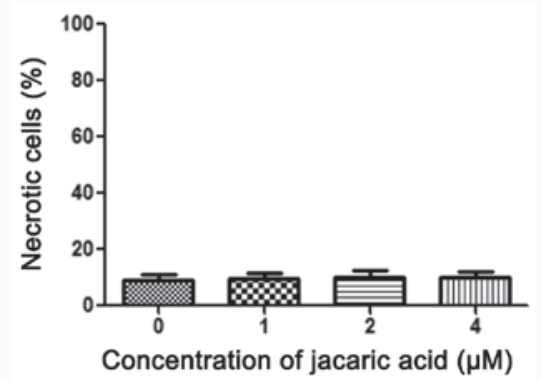

Figure 2. Effect of jacaric acid on the viability of the human mast cell line-1 (HMC-1) cells. (A) HMC-1 cells were incubated with different concentrations of jacaric acid at $37^{\circ} \mathrm{C}$ for $72 \mathrm{~h}$. Cells treated with $0.02 \%$ ethanol acted as the control. The cell viability was determined by the MTT reduction assay. The results are expressed as the mean percentage of cell viability \pm standard error (SE) of quadruplicate cultures; ${ }^{* * * *} \mathrm{P}<0.001$. (B and C) HMC-1 cells were pre-treated with either different concentrations of jacaric acid or $0.02 \%$ ethanol at $37^{\circ} \mathrm{C}$ for $72 \mathrm{~h}$, followed by Iono- and phorbol 12 -myristate 13 -acetate-sensitization at $37^{\circ} \mathrm{C}$ for $6 \mathrm{~h}$. (B) Cell viability was determined by the trypan blue exclusion assay, and the results are expressed as mean percentage of cell viability \pm SE. (C) Following incubation, the cells were stained with annexin V-green fluorescent protein and propidium iodide, and the fluorescence intensity was measured by FASCSanto ${ }^{\mathrm{TM}}$ flow cytometer. The percentage of necrotic cells was quantified and expressed as mean \pm SE.

of NAG and tryptase from HMC-1 cells was determined. As shown in Table I, pre-treatment of HMC-1 cells with jacaric acid at $4 \mu \mathrm{M}$ could significantly suppress the secretion of NAG 
A

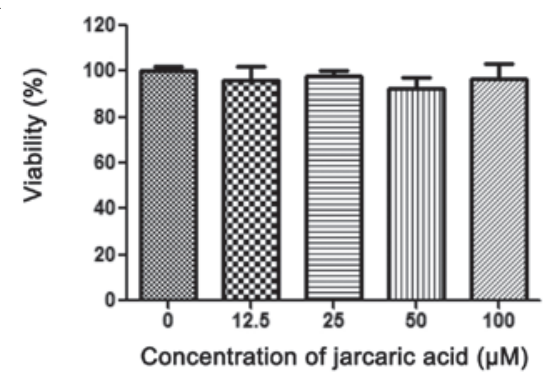

C

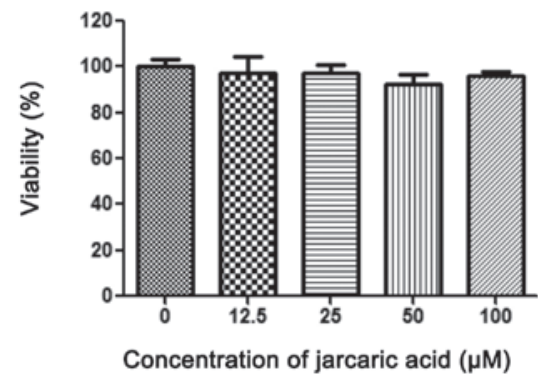

B

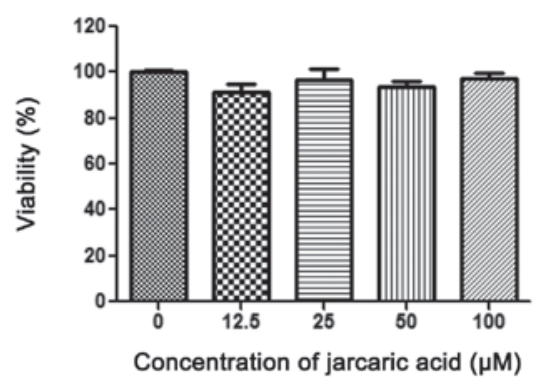

D

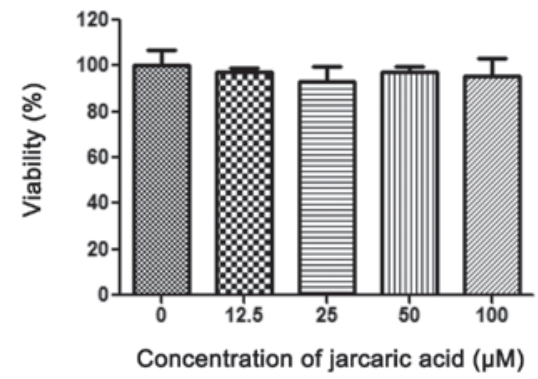

Figure 3. Jacaric acid does not exhibit cytotoxicity on the human peripheral blood mononuclear cells. Human peripheral blood mononuclear cells were incubated with different concentrations of jacaric acid at $37^{\circ} \mathrm{C}$ for (A) 6 , (B) 24 , (C) 48 or (D) $72 \mathrm{~h}$. Cells treated with $0.02 \%$ ethanol acted as the control. Cell viability was determined by the MTT reduction assay. The results are expressed as the mean percentage of cell viability \pm standard error of quadruplicate cultures.

A

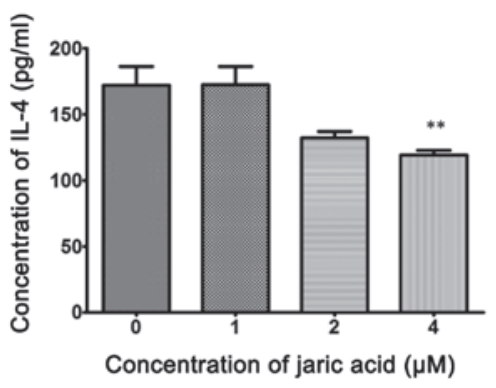

B

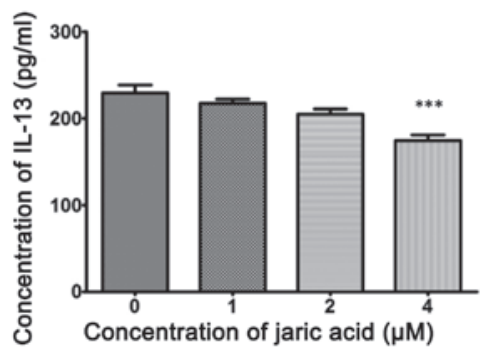

Figure 4. Jacaric acid reduces the secretion of interleukin (IL)-4 and IL-13 in human mast cell line-1 (HMC-1) cells. HMC-1 cells were incubated with different concentrations of jacaric acid at $37^{\circ} \mathrm{C}$ for $72 \mathrm{~h}$. Cells treated with $0.02 \%$ ethanol acted as the control. The treated cells were further sensitized with Iono and phorbol 12-myristate 13 -acetate at $37^{\circ} \mathrm{C}$ for $6 \mathrm{~h}$. The concentrations of (A) IL-4 and (B) IL-13 were quantified by ELISA kit according to manufacturer's instructions, and the results are expressed as mean \pm standard error. ${ }^{* *} \mathrm{P}<0.01 ;{ }^{* * *} \mathrm{P}<0.001$

from sensitized HMC-1 cells. To confirm the anti-allergic effect of jacaric acid, the release of tryptase in HMC-1 cells was assessed by the Mast Cell Degranulation Assay kit. Jacaric acid could also inhibit the release of tryptase from sensitized HMC-1 cells (Table I). These results suggest that jacaric acid could alleviate the allergic response in sensitized HMC-1 cells.
Jacaric acid suppresses the secretion of Th2 cytokines in HMC-1 cells. Apart from the release of NAG and tryptase, a previous study demonstrated that the secretion of two Th2 cytokines, IL-4 and IL-13, is also a marker of allergic response upon stimulation by Iono and PMA (12). The present results showed that the secretion of IL-4 (Fig. 4A) and IL-13 (Fig. 4B) in activated HMC-1 cells was significantly reduced when the cells were pre-treated with $4 \mu \mathrm{M}$ jacaric acid.

Jacaric acid modulates the expression levels of MMP-2, MMP-9 and TIMP-1 proteins in HMC-1 cells. The recruitment and migration of inflammatory cells require degradation of extracellular matrix proteins by secreted MMP. MMP-2 and MMP-9 are considered to have a key role in tissue remodeling and repair through degradation of type IV collagen, whereas the activation of MMP is inhibited by TIMPs (17). To unravel the molecular action mechanisms underlying the anti-allergic response, the effects of jacaric acid on modulating the expression levels of MMP-2, MMP-9 and TIMP-1 proteins were examined by Western blotting (Fig. 5A). Following pre-treatment with jacaric acid, the expression levels of MMP-2 and MMP-9 proteins in sensitized HMC-1 cells were significantly decreased (Fig. 5B and C), and this was accompanied by an increase in the expression level of TIMP-1 protein (Fig. 5D), suggesting that jacaric acid may exert its anti-allergic response in activated HMC-1 cells via modulation of MMP-2, MMP-9 and TIMP-1 protein expression levels.

\section{Discussion}

Mast cells are the central effector cells in allergic response and they are also involved in the defense against pathogens, typically by cross-linking of surface immunoglobulin E (IgE) receptors, or through IgE-independent mechanisms 
A
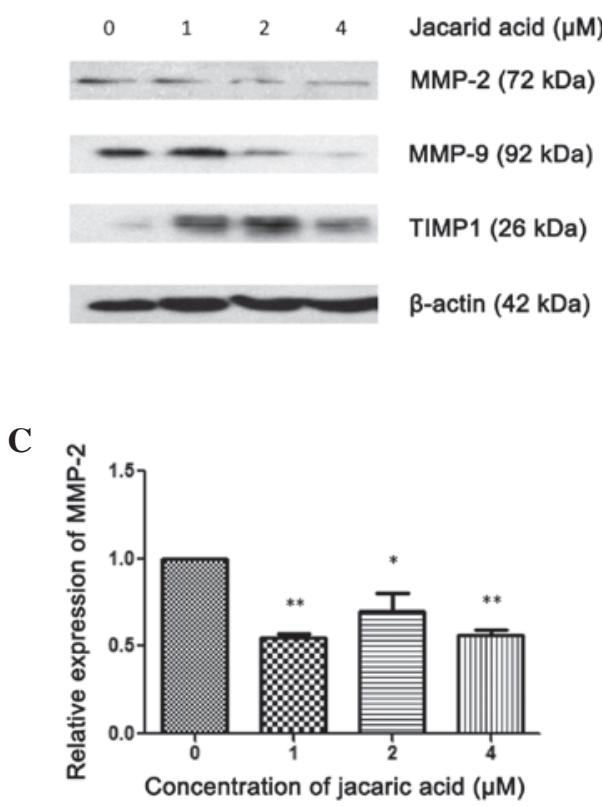

B

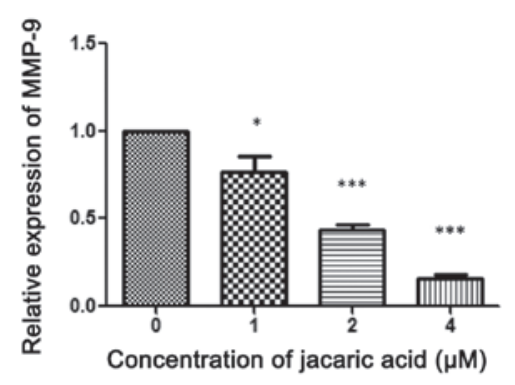

D

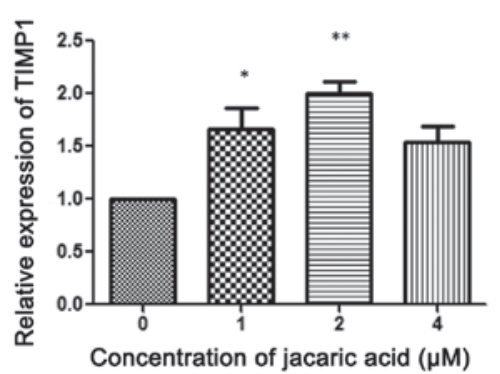

Figure 5. Jacaric acid modulates the expression levels of matrix metalloproteinase (MMP)-2, MMP-9 and tissue inhibitor of metalloproteinase-1 (TIMP-1) proteins in human mast cell line-1 (HMC-1) cells. HMC-1 cells were incubated with 1 (lane 2), 2 (lane 3) and $4 \mu \mathrm{M}$ jacaric acid (lane 4 ) at $37^{\circ} \mathrm{C}$ for $72 \mathrm{~h}$. Cells treated with $0.02 \%$ ethanol (lane 1) acted as the control. Subsequently, treated cells were further incubated with Iono and phorbol 12-myristate 13-acetate at $37^{\circ} \mathrm{C}$ for $6 \mathrm{~h}$. (A) Protein expression levels of MMP-2, MMP-9 and TIMP-1 were assayed by western blotting with $\beta$-actin protein as an internal control. (B-D) The relative expression levels of MMP-9, MMP-2 and TIMP-1 proteins compared to $\beta$-actin were quantified. Results represent mean \pm standard error. ${ }^{*} \mathrm{P}<0.05 ;{ }^{* *} \mathrm{P}<0.01 ;{ }^{* * *} \mathrm{P}<0.001$.

in non-pathogenic conditions $(15,18)$. The HMC-1 cell line was derived from a patient with mastocytosis by Butterfield et al (19) in 1988, which shows numerous characteristics of immature mast cells and contains classical mast cell-associated markers, such as the c-kit receptor, heparin, histamine and tryptase, and secretes a panel of bioactive cytokines and a variety of MMP (18). In the present study, the modulatory effects and the underlying action mechanisms of jacaric acid on the human mast cells using the HMC-1 cells as the in vitro model were examined. Pre-treatment of HMC-1 cells with jacaric acid at lower concentrations $(<5 \mu \mathrm{M})$ could reduce the secretion of inflammatory mediators, including NAG and tryptase, when the HMC-1 cells were activated with Iono and PMA. The presence of allergens or stimulants elicits an inflammatory response, which leads to the increased production and release of Th2 cytokines, such as IL-4, IL-5 and IL-13, in mast cells (17). The present results showed that the release of IL-4 and IL-13 was suppressed following the pre-treatment of activated HMC-1 cells with jacaric acid. To further elucidate the anti-allergic effect of jacaric acid on HMC-1 cells, the expression levels of MMP-2, MMP-9 and TIMP-1 proteins were examined. MMPs belong to a family of $\mathrm{Zn}$-dependent endopeptidases that are involved in the decomposition of extracellular matrix and basement membrane (20). Furthermore, MMP-2, MMP-9 and MMP-13 have a key role in tissue remodeling and repair through degradation of type IV collagen, which is the major component of the basement membrane (21). By contrast, the activation of MMP is inhibited by TIMP, and previous studies have suggested that MMP- 2 and MMP-9 are inactivated by TIMP-1 and TIMP-2 $(22,23)$. By western blotting, jacaric acid-treated HMC-1 cells showed an increase in the TIMP-1 protein expression level, accompanied by a decrease in the expression levels of MMP-2 and MMP-9 proteins. To the best of our knowledge, this is the first study demonstrating the in vitro anti-allergic effect of CLNAs on HMC-1 cells, and this is in line with earlier findings showing that CFAs, such as CLAs, may possess anti-allergic activities. For example, Jaudszus et al (24) reported that 9Z, 11E-CLA could inhibit allergic sensitization and airway inflammation through peroxisome proliferator-activated receptor- $\gamma$ dependent mechanism in mice, whereas others demonstrated that human healthy volunteers supplemented with 9Z, 11E-CLA resulted in a decreased plasma IgE level and reduced secretion of IL-5 by PBMCs $(25,26)$. Despite these earlier findings, the underlying action mechanisms for the anti-allergic effects of CFAs, such as CLAs and CLNAs, remain poorly understood and further studies are required to elucidate the mechanisms, in vitro and in vivo, for the anti-allergic activity of CFAs. In addition, whether CLNA supplementation could ameliorate other types of hypersensitivity reactions, such as the ex vivo delayed-type hypersensitivity response as shown by CLAs (25), is also a noteworthy aspect that is currently under investigation.

Collectively, the present results suggest that jacaric acid may exhibit modulatory effects on human mast cells, as it was shown to alleviate the allergic response in HMC-1 cells activated by Iono and PMA. As jacaric acid was found to exert minimal direct cytotoxicity on normal human PBMCs, and apparently was non-toxic to mice (27), further elucidation of the immunomodulatory effects of jacaric acid, in vitro and in vivo, may provide better insights for the development of jacaric acid as a potential candidate for the treatment of certain allergic disorders with minimal toxicity and fewer side effects. 


\section{References}

1. Nagao $\mathrm{K}$ and Yanagita T: Conjugated fatty acids in food and their health benefits. J Biosci Bioeng 100: 152-157, 2005.

2. Palmquist DL, Lock AL, Shingfield KJ and Bauman DE: Biosynthesis of conjugated linoleic acid in ruminants and humans. Adv Food Nutr Res 50: 179-217, 2005.

3. Takagi T and Itabashi Y: Occurrence of mixtures of geometrical isomers of conjugated octadecatrienoic acids in some seed oils Analysis by open tubular gas liquid chromatography. Lipids 16: 546-551, 1981.

4. Dilzer A and Park Y: Implication of conjugated linoleic acid (CLA) in human health. Crit Rev Food Sci Nutr 52: 488-513, 2012.

5. Wang $T$ and Lee HG: Advances in research on cis-9, trans-11 conjugated linoleic acid: A major functional conjugated linoleic acid isomer. Crit Rev Food Sci Nutr 55: 720-731, 2015.

6. Tanaka T, Hosokawa M, Yasui Y, Ishigamori R and Miyashita K: Cancer chemopreventive ability of conjugated linolenic acids. Int J Mol Sci 12: 7495-7509, 2011.

7. Hennessy AA, Ross RP, Devery R and Stanton C: The health promoting properties of the conjugated isomers of $\alpha$-linolenic acid. Lipids 46: 105-119, 2011.

8. Saha SS and Ghosh M: Protective effect of conjugated linolenic acid isomers present in vegetable oils against arsenite-induced renal toxicity in rat model. Nutrition 29: 903-910, 2013.

9. Ike K, Uchida Y, Nakamura T and Imai S: Induction of interferon-gamma (IFN-gamma) and T helper 1 (Th1) immune response by bitter gourd extract. J Vet Med Sci 67: 521-524, 2005.

10. Yamasaki M, Kitagawa T, Koyanagi N, Chujo H, Maeda H, Kohno-Murase J, Imamura J, Tachibana $\mathrm{H}$ and Yamada $\mathrm{K}$ : Dietary effect of pomegranate seed oil on immune function and lipid metabolism in mice. Nutrition 22: 54-59, 2006.

11. Wong CK, Tsang CM, Ip WK and Lam CW: Molecular mechanisms for the release of chemokines from human leukemic mast cell line (HMC)-1 cells activated by SCF and TNF-alpha: Roles of ERK, p38 MAPK, and NF-kappaB. Allergy 61: 289-297, 2006.

12. Yanagihara Y, Kajiwara K, Basaki Y, Ikizawa K, Akiyama K and Saito H: Induction of human IgE synthesis in B cells by a basophilic cell line, KU812. Clin Exp Immunol 108: 295-301, 1997.

13. Han XQ, Yue GL, Yue RQ, Dong CX, Chan CL, Ko CH, Cheung WS, Luo KW, Dai H, Wong CK, et al: Structure elucidation and immunomodulatory activity of a beta glucan from the fruiting bodies of Ganoderma sinense. PLoS One 9: e100380, 2014

14. Liu WN and Leung KN: Apoptosis- and differentiation-inducing activities of jacaric acid, a conjugated linolenic acid isomer on human eosinophilic leukemia EoL-1 cells. Oncol Rep 32: 1881-1888, 2014.
15. Guhl S, Babina M, Neou A, Zuberbier T and Artuc M: Mast cell lines HMC-1 and LAD2 in comparison with mature human skin mast cells - drastically reduced levels of tryptase and chymase in mast cell lines. Exp Dermatol 19: 845-847, 2010.

16. Stone KD, Prussin C and Metcalfe DD: IgE, mast cells, basophils, and eosinophils. J Allergy Clin Immunol 125 (Suppl 2): S73-S80, 2010.

17. Mori S, Pawankar R, Ozu C, Nonaka M, Yagi T and Okubo K: Expression and roles of MMP 2, MMP 9, MMP 13, TIMP 1 , and TIMP 2 in allergic nasal mucosa. Allergy Asthma Immunol Res 4: 231-239, 2012.

18. Galinsky DST and Nechushtan H: Mast cells and cancer - no longer just basic science. Crit Rev Oncol Hematol 68: 115-130, 2008.

19. Butterfield JH, Weiler D, Dewald G and Gleich GJ: Establishment of an immature mast cell line from a patient with mast cell leukemia. Leuk Res 12: 345-355, 1988.

20. Murphy G and Docherty AJP: The matrix metalloproteinases and their inhibitors. Am J Respir Cell Mol Biol 7: 120-125, 1992.

21. Salib RJ and Howarth PH: Remodelling of the upper airways in allergic rhinitis: Is it a feature of the disease? Clin Exp Allergy 33: 1629-1633, 2003.

22. Nagase H: Activation mechanisms of matrix metalloproteinases. Biol Chem 378: 151-160, 1997.

23. Shimizu T, Kanai K, Asano K, Hisamitsu T and Suzaki H: Suppression of matrix metalloproteinase production in nasal fibroblasts by tranilast, an antiallergic agent, in vitro. Mediators Inflamm 2005: 150-159, 2005.

24. Jaudszus A, Krokowski M, Möckel P, Darcan Y, Avagyan A, Matricardi P, Jahreis G and Hamelmann E: Cis-9, trans-11-conjugated linoleic acid inhibits allergic sensitization and airway inflammation via a PPARgamma-related mechanism in mice. J Nutr 138: 1336-1342, 2008.

25. Song HJ, Grant I, Rotondo D, Mohede I, Sattar N, Heys SD and Wahle KWJ: Effect of CLA supplementation on immune function in young healthy volunteers. Eur J Clin Nutr 59: 508-517, 2005.

26. Turpeinen AM, Ylönen N, von Willebrand E, Basu S and Aro A: Immunological and metabolic effects of cis-9, trans-11-conjugated linoleic acid in subjects with birch pollen allergy. Br J Nutr 100: 112-119, 2008.

27. Shinohara N, Tsuduki T, Ito J, Honma T, Kijima R, Sugawara S, Arai T, Yamasaki M, Ikezaki A, Yokoyama M, et al: Jacaric acid, a linolenic acid isomer with a conjugated triene system, has a strong antitumor effect in vitro and in vivo. Biochim Biophys Acta 1821: 980-988, 2012. 